\title{
Delineating the Prostate Boundary on TRUS Image Using Predicting the Texture Features and its Boundary Distribution
}

\author{
Sunhwa Park*, Hoyong Kim**, Yeong Geon Seo*
}

\section{Abstract}

Generally, the doctors manually delineated the prostate boundary seeing the image by their eyes, but the manual method not only needed quite much time but also had different boundaries depending on doctors. To reduce the effort like them the automatic delineating methods are needed, but detecting the boundary is hard to do since there are lots of uncertain textures or speckle noises. There have been studied in SVM, SIFT, Gabor texture filter, snake-like contour, and average-shape model methods. Besides, there were lots of studies about 2 and 3 dimension images and CT and MRI. But no studies have been developed superior to human experts and they need additional studies. For this, this paper proposes a method that delineates the boundary predicting its texture features and its average distribution on the prostate image. As result, we got the similar boundary as the method of human experts.

Keywords : boundary distribution, texture feature, prostate, prostate boundary, ultrasound image

\section{TRUS 영상에서 질감 특징 예측과 경계 분포를 이용한 전립선 경계 분할}

박순화*, 김호용**, 서영건*

요 약

일반적으로 병원의 의사들은 눈으로 전립선 영상을 보고 수동으로 전립선과 배경의 경계를 구분하 였다. 그러나 수동으로 자르는 과정은 너무 많은 시간을 소모하고 의사에 따라 다양한 경계가 추출되 었다. 이런 문제를 줄이기 위해 자동 추출방식이 필요하게 되었지만, 전립선 경계의 정확한 추출은 작 은 잡음이나 옅은 경계로 인하여 상당히 어려운 일이다. 지금까지 SVM, SIFT, 가버 텍스처 필터, 뱀형 상 윤곽선 방법, 평균형상모델들과 같은 많은 연구가 진행되었다. 게다가, 2 차원뿐만 3 차원 영상, CT나 MRI 등에 관한 연구도 진행되었다. 하지만 아직까지 인간 전문가가 가진 경험을 뛰어 넘는 기술은 개 발되지 않았으며, 많은 추가적인 연구를 필요로 하고 있다. 이에 본 논문에서는 전립선 영상의 경계의 평균적인 분포와 경계의 질감 특징을 예축하여 경계를 추출하는 방법을 제안한다. 실험 결과, 의사의 추출 방법과 유사한 경계를 얻을 수 있었다.

키워드: 경계 분포, 질감 특징, 전립선, 전립선 경계, 초음파 영상

\section{Introduction}

\footnotetext{
※ Corresponding Author: Yeong Geon Seo

Received: Dec. 15, 2016

Revised: Dec. 28, 2016

Accepted: Dec. 31, 2016

* Gyeongsang National University, Dept. of Computer Science and Graduate School of CCBM email:young@gnu.ac.kr

** Youngjin College, School of Computer Information
}

Ultrasound imaging is a widely used technology for diagnosing the cancers of prostate image[1,2]. Especially, TRUS (Transrectal Ultrasound) prostate images are captured more easily and with lower cost. In (Figure 1), an example of TRUS image capture is shown. US imaging is the main modality for prostate cancer diagnosis and treatment, due to many of its clinical 
advantages, expensive and easy to use. Accurate delineation of prostate boundaries from US images plays an important role in many prostate-related applications such as the accurate placement of the needles and biopsy, the assignment of the appropriate therapy in cancer treatment, and the measurement of the prostate gland volume [1]. Moreover, the shape of the prostate in US images is considered as an important indicator for staging prostate cancer. But, because the boundaries between prostate and nonprostate of the image are ambiguous, an automatic extraction of the boundaries has some difficulties. Such that, they are very weak texture structure, low contrast, fuzzy boundaries, speckle noise and shadow regions.

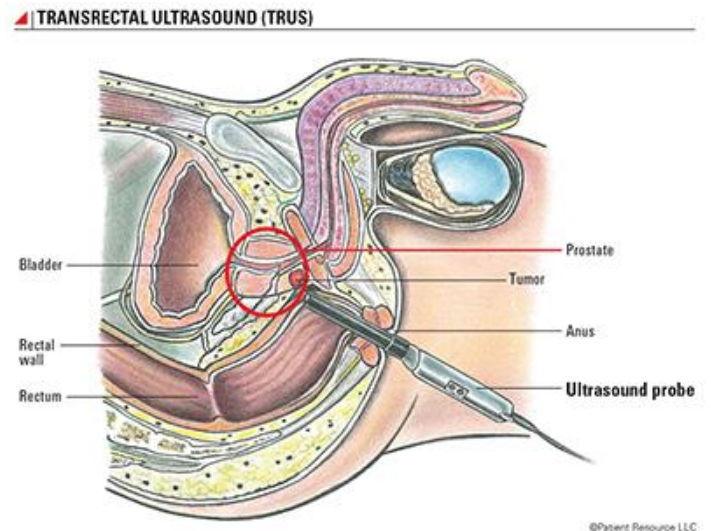

(Figure 1) TRUS image capture and the probe

To cope with these problems, different methods have been studied. [3] developed a deformable segmentation using Gabor-support vector machine based $3 \mathrm{D}$ prostate images. [4] presented a new paradigm for the edge-guided delineation, providing the algorithm-detected prostate edges as a visual guidance for the user to manually edit. [5] designed a statistical shape model for outlining prostate boundary from 2D TRUS images. [6] extracted the boundary using SVM(Support Vector Machine) and snake-like contour. To extract texture features it used Gabor filter bank and SVM to get each feature of prostate and nonprostate in learning process. [7] proposed a prostate segmentation method using average shape mode and SIFT feature. [8] extracted the prostate boundary using Gabor texture and snake-like contour. This method determined the boundary to be smooth curve on the final boundary extracting step. [9] detected the boundary with Gabor texture features and average shape model. [10] presented an automatic segmentation of the prostate in $3 \mathrm{D}$ TRUS images by extracting texture features and by statistically matching geometrical shape of the prostate. Until now on, there have been many studies, but it is to hard to get precise boundary caused by the prostate position and its image condition. So we proposes a method that delineates the boundary predicting its texture features and its average distribution on the prostate image.

\section{Related Works}

\subsection{TRUS Prostate Boundary}

The base and apex parts of prostate are generally unclear or broken, since these boundaries are almost parallel to US beams of the transducer as you can see in (Figure 2). Besides, the image can be shot upside down. Therefore, the images of the two parts are almost impossible to delineate the boundaries without reference of their neighbor's boundaries. Several methods were proposed for the above problems.

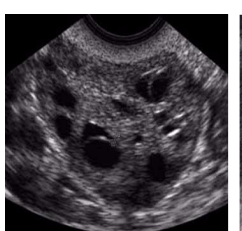

(a)

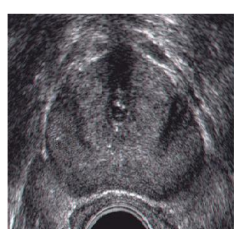

(b)

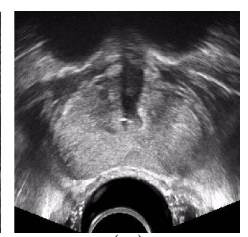

(c)
(Figure 2) (a) upside down image (b) no straight lines image (c) two probes image 
A deformable segmentation method was proposed. The boundaries of deformable model is subsequently driven to the boundary between the tentatively labeled prostate and nonprostate tissues, while its shape is limited by pre-constrained shape. Tentative tissue labeling and subsequent deformation are repeated until they converge to the boundary in the prostate images. An automatic segmentation for the prostate from 2D TRUS using adaptive learning local shape statistics was proposed. Another method is to use 3D segmentation. Using 3D image the method gets the statistical boundary model from apex to base. Disadvantages of the method can't find abnormal protrusions like tumor. The boundaries of an image are adjusted within a certain limit of the pre-acquired 3D model.

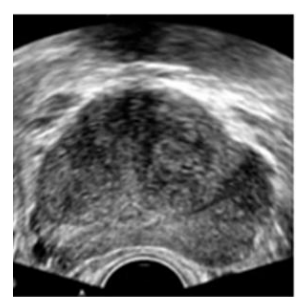

(a)

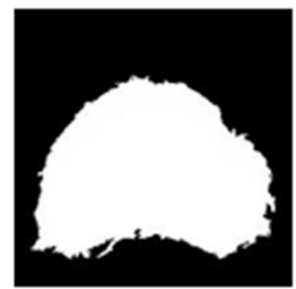

(c)

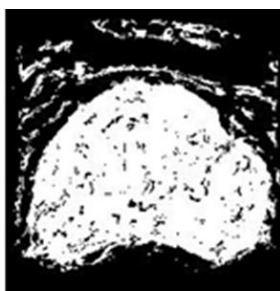

(b)

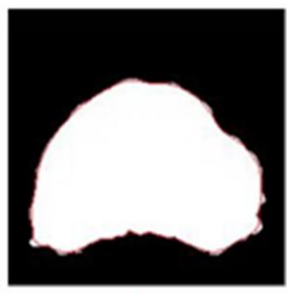

(d)
(Figure 3) (a) test image, (b) their predicted

labels (c) labels after excluding wrong classified pixels, (d) labels after removing protrusions and smoothing

\subsection{Existing Methods}

Delineating the prostate boundary is easy on which its boundary is clear as MRI and CT images, but hard on TRUS images which it is uncertain. The followings are the existing studied results to compare to our proposed method in this paper.

[6] extracted the boundary using SVM and snake-like contour. To extract texture features it used Gabor filter banks and SVM to get each characteristic between prostate and nonprostate on learning process. SVM decides whether each pixel is included on prostate or nonprostate by learning. (Figure 3) is the images classified by this method. (a) is original image, (b) is labeled image by SVM that the white pixels are prostate and the black ones are background(nonprostate), (c) is the image that the islands are removed, and (d) is the determined image of the boundary using snake-like contour of (c). [7] proposed the prostate separating method using an average shape model and SIFT features. The specific steps are the followings. First step finds the probe and the straight lines using edge distribution, second one finds 3 patches centered on the average model. The patches are used to compare with the features of prostate and nonprostate. Third one compares how similar the 3 patches are to each block. Last one uses the abstract boundaries got from first step and the one got from third step for the final segmentation. The first step of SIFT algorithm determines the size and position of the features and find the interest points that need Gaussian pyramid using DoG(Difference of Gaussian)(Equation 1 and 2). Here, $\mathrm{G}(\mathrm{x}, \mathrm{y})$ is Gaussian filter. The second step erases wrong points to be used as the candidates of key points to extract the features. The third step determines the neighbor's orientation and size of the key points. The final step gets the slope size neighboring to the points.

$$
\begin{array}{ll}
L(x, y, \sigma)=G(x, y, \sigma) \otimes I(x, y) & \text { (eq. 1) } \\
G(x, y, \sigma)=\frac{1}{2 \pi \sigma^{2}} e^{\frac{\left(x^{2}+y^{2}\right)}{2 \sigma^{2}}}
\end{array}
$$

[8] extracted the prostate boundary using 
Gabor texture features and snake-like contour. This method determined the boundary to be soft curve during determining it in final outline extraction step. Preprocessing step finds the probe and background area after histogram smoothing, stick filtering and morphological filtering. Next step makes Gabor filter banks, executes convolution with them, and extracts Gabor features that will be entered with 3 steps and used on learning. Last step determines whether each pixel is included on prostate or nonprostate and partly compensates the wrong classified pixel, and determines the abstract boundary that will used to determine the final boundary using snake-line contour.

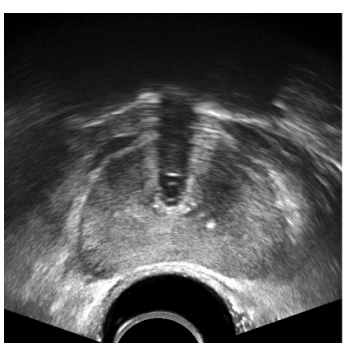

(a)

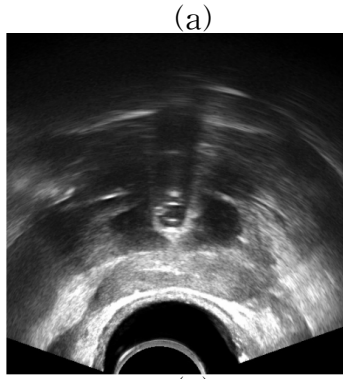

(c)

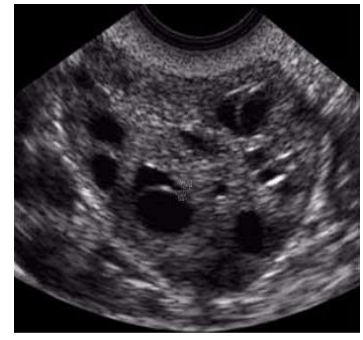

(b)

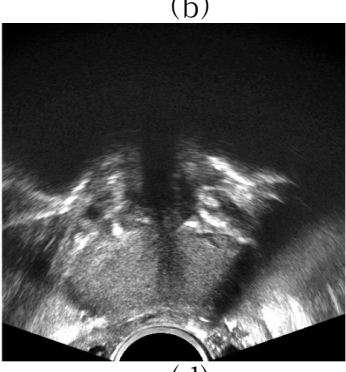

(d)
(Figure 4) (a) center image (b) normal Image (c) base image (d) apex image

\subsection{Problems of the Existing Methods and Necessity of a New Method}

Prostate shape is similar to bean's one and this shape consists of 3 dimensional image which are series of 2 dimensional images which is fan-shaped. TRUS prostate image is filmed using probe through per rectum.
Therefore, the probe is always on middle of up and down of the image and totally black arc shape. The straight lines on both sides of probe are not filming part and appeared dark. As (Figure 4), the position of probe can be down or up of the image but the straight lines can be appeared or not and most of TRUS prostate image is not clear on the boundary of prostate and nonprostate. Also, the prostate shape, its size and its position differ from individual to individual, and according to the image size its shape can be differed. So there is no common shape applying to prostate boundary segmentation. As (Figure 4), ultrasound prostate image is hard to delineate the boundary caused by the noises. Especially, its base part and apex part are not clear and broken, and impossible to draw the boundary without referencing the neighbor's one. That's why the two parts are parallel with ultrasound beam[6]. Boundary segmentation is hard to precisely segment because TRUS image is not clear and to express them. Nevertheless, there have been studied several methods.

To cope with the problems, in this paper, we propose a method that the boundary is spirally investigated from the center of image to the outside because the center of the boundary is on the center of the image, and at this time the texture features would be taken. The features have their orientation and size. The texture features using here have parallel texture to the probe and, are dark to the inside direction and bright to the outside one from the center of the image. To find those features the method search with reverse direction of onion peel from the center. Finally the prostate boundary can be taken on connecting the given textures. 


\section{Exploring Boundary Using Texture Features}

\subsection{Overall Structure of the Method}

The proposed method is composed of preprocessing, extraction of Gabor texture features, grouping of them like with like and delineation of contour. In preprocessing, histogram equalization enhances the contrast of images by transforming the values in an intensity image, so that the histogram of the output approximately matches a specified histogram. Histogram equalization considers a discrete gray scale image, $x$, and lets ni be the number of occurrences of gray level, i. The probability of an occurrence of a pixel level, $\mathrm{i}$ in the image is

$$
p_{x}(i)=p(x=i)=\frac{n_{i}}{n}, 0 \leq i<L
$$

Here, $\mathrm{L}$ is the total number of gray levels in the image, $\mathrm{n}$ is the total number of pixels in the image, and px(i) is in fact the image's histogram for pixel value $i$.

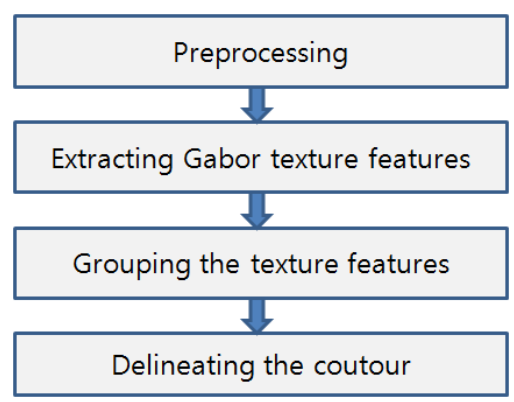

(Figure 5) Procedure of the proposed method

\subsection{Extracting Gabor texture features}

Gabor filter bank is obtained by the dilation and rotation of the mother function. Here, we use that total numbers of the orientations are $\mathrm{K}=4$, the scale numbers of the scales are $\mathrm{S}=2$. So the basic rotation and scale factors are $\psi=$ $\pi / \mathrm{K}$ and $\mathrm{a}=(\mathrm{Uh} / \mathrm{Ul}) 1 / \mathrm{S}-1$ respectively. Uh and $\mathrm{Ul}$ are parameters that determine the frequency range of the Gabor filter bank. We use Uh=0.1 and $\mathrm{Ul}=0.025$. Using the scale variables and the rotation variables, the $(\mathrm{s}, \mathrm{k})$ th Gabor filter is

$$
\begin{aligned}
& g_{s, k}(x, y)= \\
& a^{s} g\left(a^{s}(x \cos (k \psi)+y \sin (k \psi)) a^{s}(-x \sin (k \psi)+y \cos (k \psi))\right)
\end{aligned}
$$

Gabor filter bank has two important properties, the frequency spectrum of the filter bank has a multiscale and multiorientation structure and each filter can be separated into two parts, i.e., the real part and the imaginary part. The real part is regarded as a smooth filter and the imaginary part is done as an edge detection filter. Using Gabor filter bank offers three advantages. First, it can smooth the image and remove speckle noises. Second, the multiscale structure enables hierarchical implementation. Third, the multiorientation structure enables the extractions of edge direction, edge strength and rotation-invariant features. (Figure 6) shows 2D Gabor filter bank used in the proposed method. First rows are $\mathrm{S}=1$ and second rows are $\mathrm{S}=2$. First columns are $\mathrm{K}=1$, second ones are $\mathrm{K}=2$, third ones are $\mathrm{K}=3$, and last ones are $\mathrm{K}=4$.

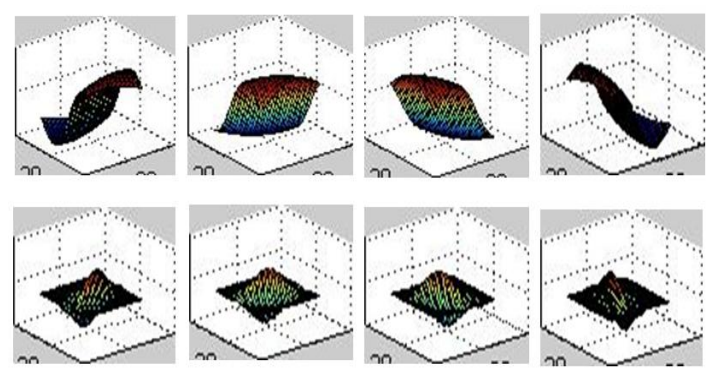

(Figure 6) 2D Gabor filter banks

The values of the features are normalized to 0-255 for display purposes. Here, it can use a number of orientations and scales, but they can generate tons of data. Also, it can use the real part Gabor features. So the proper negotiation is needed. In this paper, we use 8 Gabor texture features per pixel which consist 
of $\mathrm{K}=4, \mathrm{~S}=2$ and the imaginary part Gabor features.

\subsection{Grouping texture features}

As (Figure 7), this process explores the texture features from the center to the outside counterclockwise. Texture features of prostate are that the inside ones are dark and the outside ones are light relatively accordant to the exploring direction (Figure 8). When the process intensively gets the area having those features, grouping of them will be succeeded. To select a group which can be a boundary candidate of the texture features, this uses $6 \times 6$ mask which executes arithmetic operation for all pixels. The mask is different according to the exploring directions, the division line depends on the inclined angle based on the center. For example, on exploring the true north of the center, the mask consists of that 3 upper lines are 1s and 3 lower lines are 0 s. The condition to be a candidate of boundary is that difference of the brightness between 0 's pixels and 1 's pixels is bigger that the threshold.

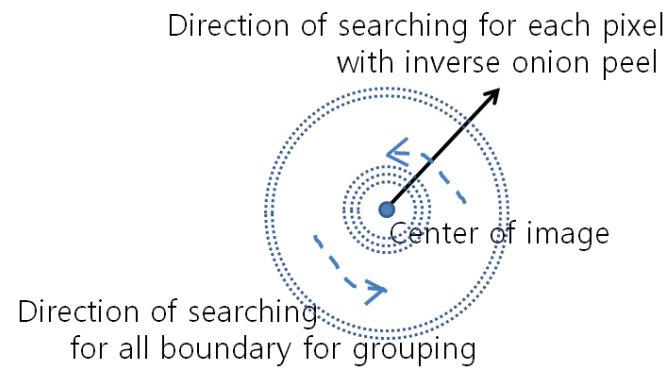

(Figure 7) Directions for searching for and grouping texture features

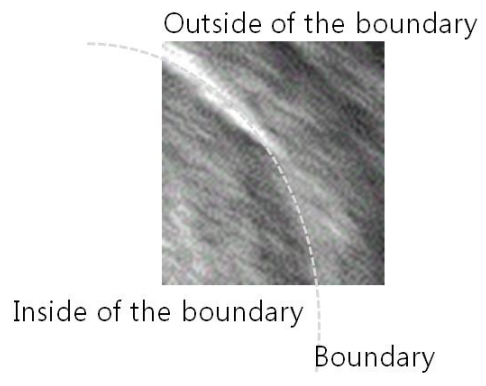

(Figure 8) Distended image near a prostate boundary

\subsection{Delineating contour}

To get the final contour, this method delineates natively the group features almost circularly with the axis which is the center of image. To delineate them natively, it uses an algorithm which makes softly the line. A contour of a $2 \mathrm{D}$ region is defined by an ordered set of points where the neighboring elements contain the neighboring points. Such representation can be obtained with many techniques such as boundary tracing and chain codes. In a simple $2 \mathrm{D}$ point set or a curve the points do not have to line in a specific order. The contour smoothing is done by projecting all the contour points onto the local regression line. For each point, $\mathrm{N}$ neighboring points which lie on the contour are sampled on each side and a local regression line is computed. Then the current point is projected on this line. Applying this algorithm to all the points smooths the contour and in a way brings the points closer. $2 \mathrm{~N}+1$ is the number of total points contributing to the computation of the local regression line. The higher the number of point is, the smoother the curve is. Because of the linear nature of fitting, when too much smoothing is desired, some important features such as protrusions may be loosed. This in a way is a wrong over-smoothing. A way to be less prone to such errors is to use Gaussian weighted least squares fit. 


\section{Experiments and Evaluation}

\subsection{Experimental Method}

This paper proposes a method that extracts texture features during exploring the image from the center to the outside and connects the grouped features to find a prostate boundary. The method uses the fact that texture features are distributed as circular shape from the center of the image. To prove the superiority of the method to the existing methods, it uses the images like (Figure 9) as test data and shows the superiority with experimentation. The test images are all gray ones and these resolutions are $512 \times 512$. In the figures, (a) is scanned deepen, (b) is an image that two straight lines are not seen, (c) is a normal image, and (d) is an image that probe and straight lines are above. Here, the existing methods [7] and [9] can not find it using (b) and (d) because the images don't have them or are upside down.

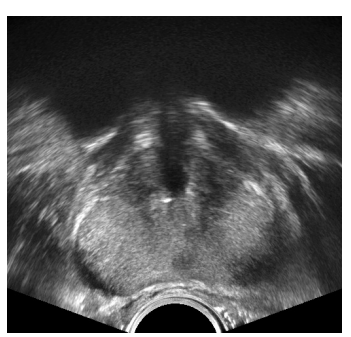

(a)

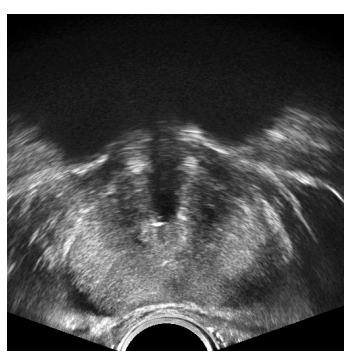

(c)

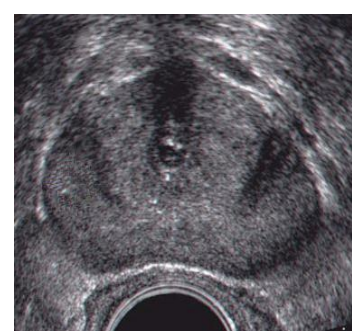

(b)

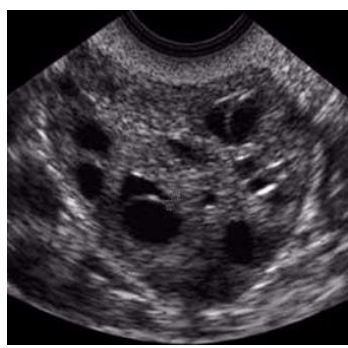

(d)
(Figure 9) Test images

\subsection{Performance Evaluation}

To show the proposed method is better than the existing methods, it uses differences of boundary between human experts' and a method. Make sure even human experts have differences of their drawn boundaries, but they are very similar, but not same. For comparison, the difference (D) comes from the following equation. Here, HM means the matrix of pixels for human expert's boundary, GM means the one for a given method's boundary being compared. The difference means that the value is bigger than \pm 1 .

$$
\begin{gathered}
D=\text { rate of difference for all pixels of } G M \\
\text { and } H M
\end{gathered}
$$

Using equation 5, the results of evaluation are shown on <Table 1>. Although the difference between the boundaries of human expert and the other methods exists, Ds are small values because the size of the prostates occupies the big region. In $<$ Table $1>$, the values mean $\mathrm{D}$, how much different between the boundaries of human and a given method is. And 'not found' means that the method can not find the boundary as any datum point does not exist. (Figure 10) shows the images that the proposed method delineated the boundary which is similar to one of expert.

\begin{tabular}{r|c|r|r|r}
\hline $\begin{array}{r}\text { test } \\
\text { ima } \\
\text { ges }\end{array}$ & \multicolumn{4}{|c}{$\mathrm{D}$} \\
\cline { 2 - 5 } & {$[6]$} & {$[7]$} & {$[9]$} & $\begin{array}{r}\text { propose } \\
\text { dethod }\end{array}$ \\
\hline $\mathrm{a}$ & 0.032 & $\begin{array}{r}0.037 \\
\text { not } \\
\mathrm{b}\end{array}$ & $\begin{array}{r}0.030 \\
\text { not } \\
\text { found }\end{array}$ & 0.030 \\
0.059 & 0.055 \\
$\mathrm{c}$ & 0.044 & $\begin{array}{r}0.42 \\
\text { not } \\
\text { found }\end{array}$ & $\begin{array}{r}\text { not } \\
\text { found }\end{array}$ & 0.046 \\
$\mathrm{~d}$ & 0.045 & 0.039 \\
\hline
\end{tabular}

$<$ Table 1> Comparisons for each experimental image 


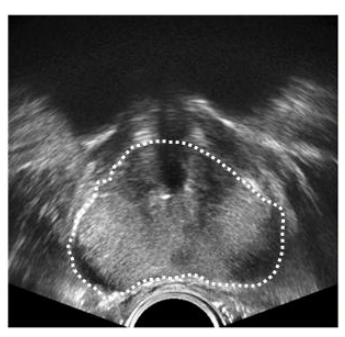

(a)

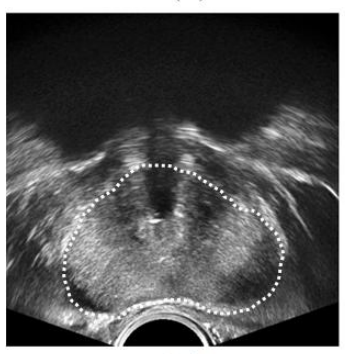

(c)

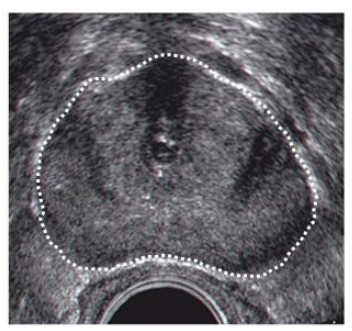

(b)

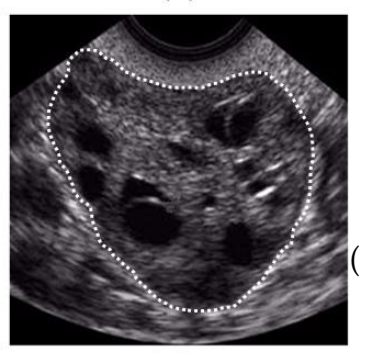

(d)
(Figure 10) Experimental results of the proposed method

\section{Conclusion}

In this paper, we proposed a method that delineates the boundary predicting its texture features and its average distribution on the prostate image. The method has an idea that the boundary is spirally investigated from the center of image to the outside because the center of the boundary is on the center of the image, and at this time the texture features would be taken. As the features have their own orientation and size, to find them the method explored image with reverse direction of onion peel from the center. As the results, we could get better performance than the existing methods.

\section{References}

[1] A. Chakraborty, L. H. Staib, and J. S. Duncan, "Defor mable boundary finding in medical images by integr ating gradient and region information," IEEE Trans. Med. Imag., Vol. 15, No. 6, Dec. 1996, pp. 859 - 870.
[2] P. D. Grimm, J. C. Balsko, and H. Ragde, "Ultrasound guided transperineal implantation of iodine 125 and palladium 103 for the treatment of early stage prosta te cancer," Atlas Urol. Clin. No. Amer., Vol. 2, 1994, pp. $113-125$.

[3] Y.Zhan and D. Shen, "Deformable Segmentation of 3-D Ultrasound Prostate Images Using Statistical Texture Matching Method", IEEE Trans. on Medica 1 Imaging, Vol. 25, March 2006, pp.245-255.

[4] S. D. Pathak, and etc., "Edge-guided boundary deline ation in prostate ultrasound images", IEEE Trans. Med. Imag., Vol. 19, No. 12, Dec. 2000, pp. 1211 - 121 9.

[5] D. Shen, Y. Zhan, and C. Davatzikos, "Segmentation prostate boundaries from ultrasound images using statistical shape model," IEEE Trans. Med. Imag., Vol. 22, No. 4, Apr. 2003, pp. 539 - 551.

[6] J. Park and etc., "A Prostate Segmentation of TRUS Image using Support Vectors and Snake-like Conto ur", Journal of The Korea Society of Computer and Information, Vol. 17, No. 12, pp. 101-109, Dec. 2012.

[7] S. Kim and etc., "A Prostate Segmentaiton of TRUS Image using Average Shape Model and SIFT Featu res", KIPS Transaction of Software and Data Engin eering, Vol. 1, No. 3, pp. 187-194, Dec. 2012.

[8] S. Kim and etc., "A Prostate Segmentation using Gab or Texture Features and Snake-like Contour", Journ al of Information Processing System, Vol. 9, No. 1, pp. 103-116, Mar. 2013.

[9] H. Kim and S. Hong, "Detecting the Prostate Bounda ry with Gabor Texture Features and Average Shape Model of TRUS Prostate Image", Journal of Digital Content Society, Vol. 16, No. 5, pp. 717-725, Oct. 2015.

[10] H. Akbari, X. Yang, L. Halig and B. Fei, “3D Segme ntation of Prostate Ultrasound Images Using Wavel et Transform”, Proc. of SPIE 7962, 2011. 


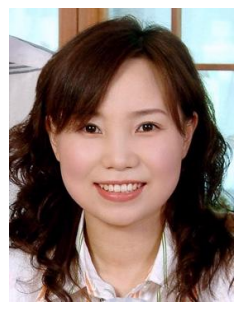

\section{Sunhwa Park}

1996 : Gyeongnam Science and Technology University of Computer Science(B.S Degree)

2000 : Gyeongsang National University of Computer Science(M.S Degree)

2015 : Doctoral Candidate in Gyeongsang National University, Graduate School of Cultural Convergence Business Model(On Ph.D Degree)

Research Interests: Multimedia, Medical Imaging and IT Cultural Convergence

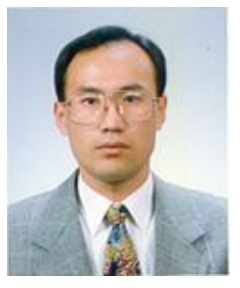

\section{Hoyong Kim}

1985 : Ulsanl University of Computer Science (B.S Degree)

1987 : Soongsil University of Computer Science (M.S Degree)

1996-now : Professor in Youngjin College, School of Computer Information

Research Interests: Multimedia, Medical Imaging, Database and Pattern Recognition

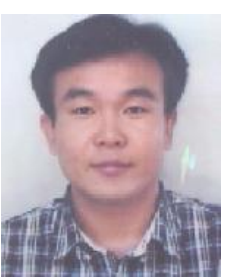

Yeong Geon Seo

1989 : Soongsil University, Dept. of Computer Science (M.S Degree)

1989-1992 : Software Developer in Trigem Computer Inc.

1997 : Soongsil University, Dept. of Computer Science (Ph.D Degree)

1997-now : Professor in Gyeongsang National University, Dept. of Computer Science and Graduate School of Cultural Convergence Business Model

Research Interests: Multimedia, Medical Imaging, Neural Network, Machine Learning and Computer Network 